\title{
TURISMO Y PUEBLOS INDÍGENAS: POLÍTICAS, IRRUPCIÓN Y REIVINDICACIÓN EN CHILE
}

\author{
TOURISM AND INDIGENOUS PEOPLES: POLICIES, IRRUPTION AND CLAIM \\ IN CHILE
}

\author{
Francisca de la Maza Cabrera ${ }^{1}$ y Enrique Calfucura Tapia ${ }^{2}$
}

\begin{abstract}
El artículo aborda el turismo en territorios indígenas desde una perspectiva que pone de relevancia las relaciones políticas y de poder, tomando como referencia experiencias en Chile. Se abordan aspectos tales como la genealogía de las políticas públicas asociadas al turismo y al turismo indígena, para luego abordar diferentes formas de expresión del turismo como violencia estructural y reivindicación política. Uno de los actores claves son los emprendedores turísticos indígenas quienes son los que lideran los procesos turísticos en sus territorios, en contraposición de los "usuarios" de los programas sociales. Asimismo, los mediadores institucionalizados son relevantes en la operación de la política pública, tanto como funcionarios o como "expertos" externos, quienes son claves tanto en el diseño como en la implementación del turismo indígena. Se presentan ejemplos de violencia estructural y reivindicación política a partir de un trabajo etnográfico en diversos territorios de Chile, principalmente la Región de la Araucanía, Bío Bío y la comuna de San Pedro de Atacama. Se concluye que estos tres aspectos, políticas públicas que promueven el turismo indígena, la violencia estructural y reivindicación territorial se van construyendo mutuamente en una tensión y apertura que genera diversas acciones desde los territorios indígenas específicos.
\end{abstract}

Palabras claves: turismo indígena, políticas públicas, emprendedor, Chile.

In this article, we discuss tourism in indigenous territories from a perspective that highlights political and power relations, taking experiences in Chile as a reference. We address issues such as the genealogy of public policies associated with tourism, particularly indigenous tourism, and then consider different forms of expression such as structural violence and political vindication. Among the key actors leading these processes in their own territories are the indigenous tourism entrepreneurs, as opposed to the "users" of social programs. Also important, in relation to public policy operation, are the institutionalized mediators who are fundamental to the design and implementation of indigenous tourism, either as officials or external "experts". Examples of structural violence and political vindication are presented based on ethnographic work in various parts of Chile, mainly in the Araucanía Region and San Pedro de Atacama. We conclude that these three aspects, public policies promoting indigenous tourism, structural violence, and land claims are mutually constructed in a tension and openness that generates various actions from specific indigenous territories.

Key words: Indigenous tourism, public policy, entrepreneur, Chile.

El artículo aborda el turismo en territorios indígenas desde una perspectiva política. Esto significa analizar el estudio del turismo desde un enfoque del poder (MacLeod y Carrier 2009) y los procesos de dominación y resistencia. Se aborda la turistificación en los territorios indígenas, considerando, por un lado, el rol de las políticas públicas y del Estado en la construcción del turismo, en específico el turismo indígena y, por otro , las acciones políticas de líderes y emprendedores indígenas referidas a las problemáticas generadas en torno al turismo en algunos de estos territorios indígenas.

El turismo en Chile se ha convertido en uno de los "motores de desarrollo", que se expresa en un significativo aumento de sus indicadores. Respecto al Producto Interno Bruto (PIB) del país, aporta directamente un $3,3 \%$ y un $10,1 \%$ si consideramos tanto los efectos directos, indirectos e inducidos (Subsecretaria de Turismo 2019). Sobre visitantes extranjeros, en el año 2000 llegaron cerca de 1,7 millones, esta cifra se incrementó hasta 5,2 millones en el año 2018, lo que significó una tasa anual de crecimiento del 5,9\% durante el periodo. El sector ha llegado a posicionarse como el cuarto más importante en términos de exportaciones a nivel nacional.

Uno de los principales atractivos, posicionando a Chile como destino turístico, es su oferta referida al Turismo de Intereses Especiales y, particularmente, al Turismo Aventura (Fernández et al. 2015). Esto ha sido relevado a nivel internacional con diversos

\footnotetext{
1 Instituto de Historia y Campus Villarrica, Pontificia Universidad Católica de Chile, Villarrica, Chile. fcadelamaza@uc.cl

2 Facultad de Economía y Empresa, Universidad Diego Portales, Santiago, Chile. enrique.calfucura@udp.cl
}

Recibido: noviembre 2019. Aceptado: septiembre 2020.

http://dx.doi.org/10.4067/S0717-73562021005001802. Publicado en línea: 29-septiembre-2021. 
reconocimientos como Lonely Planet, World Travel Award y National Geographic (El Mercurio 2017; Fedetur 2019). Los atractivos principales son los de tipo paisajístico y natural, algunos de los cuales se encuentran en áreas silvestres protegidas y, en ocasiones, se incorpora la cultura local.

Los principales destinos en Chile coinciden con territorios históricos de los pueblos indígenas, como son la Isla Rapa Nui y San Pedro de Atacama. En la última década, el turismo ha traspasado estos clásicos destinos a otros emergentes, muchos de ellos con fuerte presencia indígena como es la Región de la Araucanía, Bío Bío y regiones aledañas en el Gulumapu ${ }^{1}$ (Figura 1).

A partir de este contexto, el artículo busca contribuir desde una perspectiva teórica y metodológica al estudio del turismo desde lo político, considerando que el turismo es un tema que en forma creciente afecta la vida de las personas, ya sea como habitantes de lugares turistificados, como emprendedores turísticos o como turistas. La propuesta plantea que estos efectos se expresan con fuerza cuando dentro de esta estructura se incorporan los pueblos indígenas que habitan en territorios con demandas políticas y problemáticas históricas en relación al Estado y la sociedad nacional.

Este artículo se enmarca en una investigación mayor con un equipo interdisciplinario ${ }^{2}$ que busca la comprensión de la relación entre turismo y pueblos indígenas en Chile. Metodológicamente, el estudio es etnográfico a partir de un trabajo de campo intermitente en territorios indígenas turistificados que se inicia el año 2017. El trabajo de campo considera periodos de una o dos semanas varias veces durante el año para interactuar en los espacios turísticos con los diferentes agentes como son los turistas, los "emprendedores" turísticos indígenas y no indígenas y los funcionarios públicos, pero también ser y observar turistas. Se ha focalizado en tres territorios indígenas donde interactúan los habitantes locales y diversos agentes turísticos: San Pedro de Atacama, el territorio Lafkenmapu y Pewenmapu en las regiones de la Araucanía y Bío Bío.

También se realizó trabajo de campo desde la perspectiva de la etnografía del Estado de las prácticas estatales de instituciones que abordan el

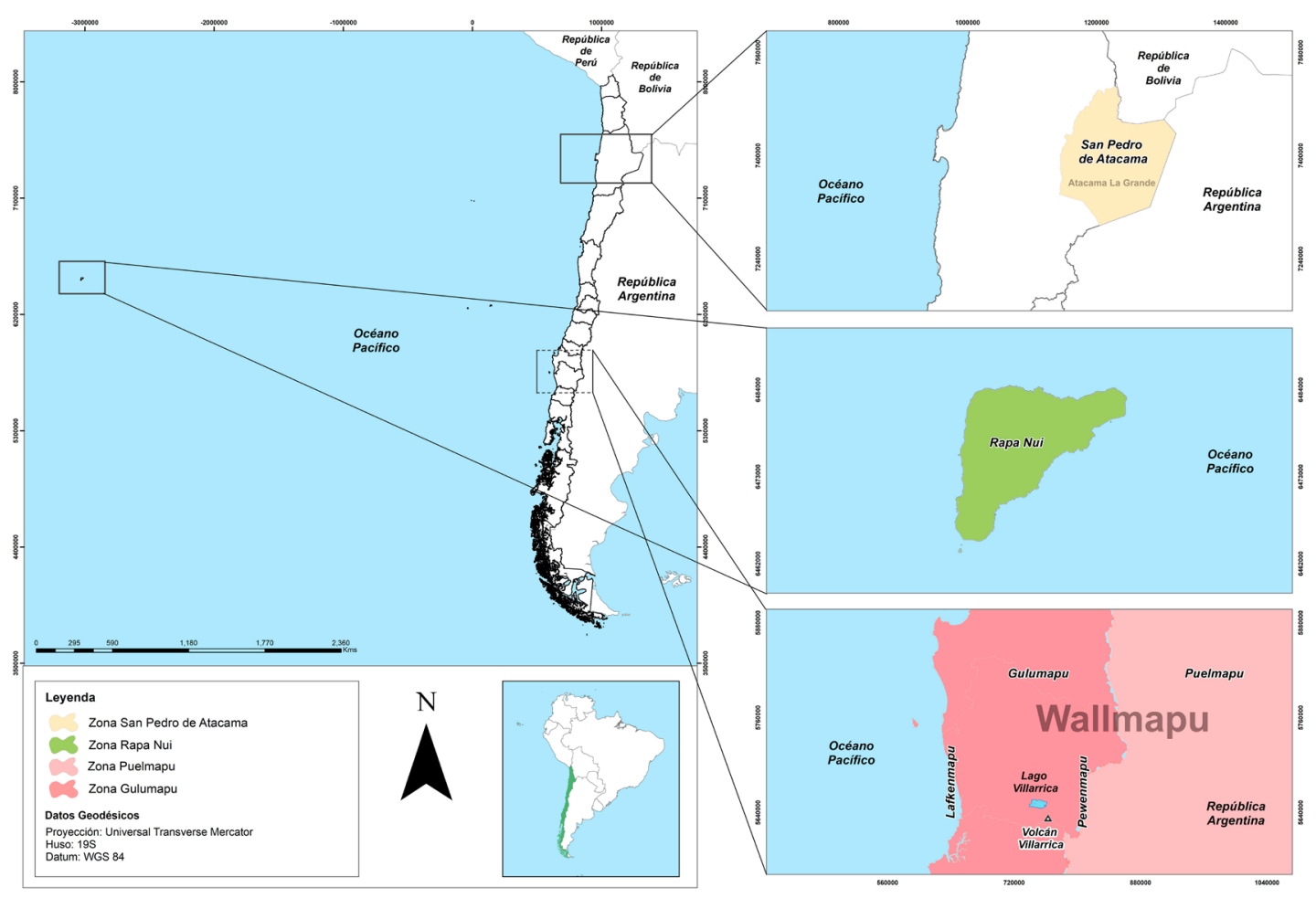

Figura 1. Destinos turísticos consolidados y emergentes señalados en el artículo.

Established and emerging tourist destinations mentioned in the article. 
tema turístico, tanto a nivel nacional, regional y local. En esta investigación se han realizado un total de 77 entrevistas en profundidad, cinco talleres de retroalimentación donde se presentaron avances del proyecto a diferentes actores locales en los tres territorios focalizados, participación en más de 15 talleres de capacitación y seminarios de instituciones públicas y privadas y en más de 30 tours locales en diferentes territorios.

Este artículo toma parte de los resultados de esta investigación abordando específicamente los aspectos relacionados a la configuración del turismo en los territorios indígenas o como los territorios se van transformando con el turismo, considerando los dilemas que se provocan con la irrupción del turismo, a partir del concepto de violencia estructural y la reivindicación política de los pueblos indígenas. Esta perspectiva permite constatar que los territorios indígenas están en una rápida transformación y en una disputa permanente entre sus habitantes originarios y los externos sobre quién tiene el control del territorio y de las acciones turísticas. Por tal motivo, este artículo quiere dar cuenta de algunos de estos múltiples espacios de interacción donde se manifiestan estas luchas y donde la antropología, en conjunto con otras disciplinas, puede aportar a desentrañar estas transformaciones que superan el turismo.

\section{Turistificación, Políticas y Emprendedor Indígena}

\section{Turistificación de los territorios indígenas}

El concepto de turistificación se asocia a la mercantilización del patrimonio cultural, entendido como un proceso por el cual se transforma un bien histórico, cultural o natural en un producto valioso en el mercado turístico (Zúñiga 2014). En este sentido, la mercantilización, apunta a la transformación de cosas en mercancía (Appadurai 1991). Es así que en el turismo cultural, los productos y prácticas culturales se transforman en mercancía, y en contextos de diversidad, como por ejemplo en relación a los pueblos indígenas, la diferencia se representa, se comercializa, se hace transable por medio de los abstractos instrumentos del mercado (Comaroff y Comaroff 2011). En este proceso continuo de turistificación, diverso y que se adapta a los territorios, entran en juego múltiples actores, se generan disputas políticas y luchas de poder por las formas de apropiación y de conversión de bienes locales en potenciales mercancías turísticas.

En particular, la turistificación de territorios indígenas se comprende cuando el turismo irrumpe, en el espacio geográfico, cultural, social y político históricamente habitado por los pueblos indígenas (Barabas 2010). En estos territorios turistificados, el turismo no puede considerarse como algo externo sino como parte de la propia cultura (Picard 2003).

Como señala Nogués-Pedregal (2019), los estudios antropológicos sobre el turismo han relevado la importancia de entender que el territorio es una construcción social en la que intervienen las múltiples prácticas e interrelaciones culturalecológicas que constituyen una sociedad, en el cual el turismo se desarrolla, que puede generar tensiones con los habitantes locales. Además estas tensiones se desarrollan en estructuras y determinaciones históricamente constituidas (Nogués-Pedregal 2019). Esto se va acentuar en territorios indígenas, en los cuales se evidencian desigualdades y jerarquías que históricamente han estado presente en las relaciones entre pueblos indígenas, Estado y Sociedad, y que reproducen inequidades económicas y sociales en la participación, acceso y resultados de los procesos de turistificación (Calfucura 2018).

Desde esta perspectiva, es relevante analizar las relaciones de poder, los conflictos entre diversos actores, las reivindicaciones, formas de control y toma de decisiones. Esto se puede expresar también en cómo en el ámbito turístico las relaciones de poder se normalizan o se profundizan, por ejemplo, cuando la turistificación de un territorio no es liderada por los indígenas, o en contradicciones entre lo que se espera del crecimiento económico, entre lo que buscan los turistas por la cultura exótica, y el deseo de los pueblos indígenas de una vida moderna (Yang y Wall 2009). Es así que el concepto de autenticidad es relevante en el turismo en contextos indígenas, entendiéndolo como dinámico, complejo y múltiple, que se superpone entre lo que esperan los turistas, lo que ofrecen los anfitriones indígenas y sus propios conceptos de lo auténtico. Esto implica el reconocimiento de autenticidades paralelas, plurales y multifacéticas en tensión (Fan et al.2020; Theodossopoulos 2013).

En Chile, se identifican al menos dos territorios indígenas altamente turistificados que son San Pedro de Atacama y Rapa Nui. Ambos espacios cuentan con un flujo permanente de turistas y su destino 
se ha consolidado a nivel nacional e internacional correspondiendo a los números 3 y 9 de lugares más visitados en Chile, respectivamente (Subsecretaria de Turismo 2019). Pero también se encuentran otros territorios en proceso de turistificación, muchos de ellos ubicados en territorios indígenas, tales como la zona de los lagos en la Región de Los Ríos o la costa lafquenche y pewenche de la Región de la Araucanía y del Bío-Bío, ya que el turismo se ha convertido en un eje potencial de desarrollo y fortalecimiento de la identidad local que ha sido promovido por las políticas públicas nacionales, regionales y locales, y que también se ha posicionado como una alternativa y complemento económico para diversos territorios y sus habitantes.

\section{Políticas públicas de turismo y turismo indígena}

Las políticas públicas se comprenden como la extensión de las decisiones de los gobernantes y que tienen una incidencia en la vida cotidiana de los ciudadanos (Barragán y Wanderley 2009; Schavelzon 2008). Estas formas ideológicas bajan con diversos intermediarios a lo local, los que tienen un rol en la toma de decisiones sobre el curso de estas políticas. Con ello, el estudio de las políticas públicas aporta al análisis de los procesos sociopolíticos de determinadas acciones estatales.

Respecto al caso de Chile, las políticas nacionales de turismo han incorporado sostenidamente desde el año 2015 el concepto de turismo indígena. Algunos autores se orientan a definir el turismo indígena como a cualquier faceta de la industria turística que involucre a los pueblos indígenas o también como aquellas actividades turísticas en las que los pueblos indígenas están directamente involucrados, ya sea mediante el control y / o haciendo que su cultura sirva como la esencia de la atracción (Nielsen y Wilson 2012). Del mismo modo, se entiende más como una forma de organización social de la diferencia más que como un atributo cultural, es más un elemento del proceso de afirmación étnica y no solamente una señal diacrítica de su identidad construida sobre relaciones de semejanza y diferencia (Pereiro 2013).

Respecto a la incorporación del concepto de turismo indígena en la política pública chilena, este se suma a una línea de políticas que buscan fortalecer el turismo que se inicia desde 1990, con el retorno a la democracia luego de la dictadura militar. Estas buscaron posicionar al turismo como una actividad económica relevante que permitiera incrementar la llegada de turistas extranjeros. Tempranamente, se constataron emprendimientos turísticos liderados por personas u organizaciones indígenas fomentados por programas estatales (como SERNATUR-Servicio Nacional de Turismo y CONADI-Corporación Nacional de Desarrollo Indígena) y por aportes privados provenientes de ONGs, fundaciones y universidades. Estas iniciativas se extienden durante esa década hacia diferentes partes del país: en el norte con población aymara asociada a artesanía y ecoturismo, en los mares australes con aportes para el desarrollo turístico de los pueblos kaweskhar y yagán, y en la región de la Araucanía con proyectos de infraestructura turística (Orígenes 2003). Asimismo, INDAP-Instituto Nacional de Desarrollo Agropecuario desde mediados de los años 1990 mantiene el Programa de Turismo Rural orientado a pequeños agricultores que permitió tempranamente que familias indígenas iniciarán experiencias en turismo. Todas estas acciones incrementaron el apoyo y financiamiento en capacitación, equipamiento, infraestructura y asesoría para el desarrollo del turismo indígena desde diversas instituciones estatales.

Asímismo, con la implementación del Programa de Desarrollo Integral para Comunidades Indígenas a comienzos del 2000, conocido como Programa Orígenes, financiado por el BID, se fortalecieron iniciativas de desarrollo productivo, entre ellas de turismo, como una apuesta al desarrollo de las comunidades indígenas (Orígenes 2003). En ese momento, se instaló el concepto de turismo indígena en la política pública chilena, como aquel que se espera que sea manejado y desarrollado por los indígenas, generalmente en sus territorios y que incorpora formas culturales propias (de la Maza 2018; Orígenes 2003).

\section{Del "usuario" al emprendedor indígena}

El "usuario" de estas políticas públicas (De la Maza 2017) se transformó en "emprendedor", concepto que se instaló con fuerza a partir de la visión neoliberal profundizada en el primer gobierno de derecha de Sebastián Piñera durante el periodo 2010-2015 (de la Maza 2016). Entre las muchas definiciones, el concepto de emprendedor puede entenderse como aquel agente con disposición al cambio, que desarrolla un negocio o emprendimiento, el cual muchas veces se asocia a cierto nivel de riesgo (Hitchcock 2000; Yang y Wall 2008).

Este concepto de emprendedor es resistido por algunos sectores indígenas que rechazan el modelo 
capitalista y se niegan a usar palabras neoliberales asociadas a lo indígena. Pero también, es rescatado e interiorizado por otros vinculados al turismo y otras actividades productivas, quienes lo utilizan como parte de su capacidad para salir adelante y de estar insertos en el mercado con una propuesta diferente, pero con respeto a su identidad.

Es así que el ser "emprendedor" se contrapone al "usuario" de los programas estatales, especialmente de las políticas indígenas ya que este último tiene una connotación asociada a la dependencia estatal y el asistencialismo (de la Maza y Bolomey 2019). A diferencia, el emprendedor turístico indígena tiene las siguientes connotaciones según sus propias voces: "con esfuerzo y sacrificio", "dar fuente de trabajo a otras personas", "nunca se cansa", "constante", "que se plantea un objetivo y está dispuesto a cambiar en el camino", "salir adelante", "ganas de hacer algo y realizarlo", "ser amable y respetuoso", "querer cambiar nuestras vidas de manera positiva", "tener ideas y buscar soluciones", "perseverante", "entregar lo mejor", "empatía", "soñador" y "busquilla"3. Es así que la apropiación del concepto de emprendedor busca superar la relación de dependencia del "usuario" y generar una forma de autonomía económica.

\section{Avanzando hacia el turismo indígena}

A nivel de políticas regionales, destaca la Región de la Araucanía, que en el año 2007 firma un Convenio SERNATUR-CONADI que permitió generar una propuesta participativa de Turismo Mapuche en la cual representantes de instituciones regionales realizaron un análisis del turismo en el pueblo mapuche, la que fue discutida en los diversos territorios de la región. En un documento, resultado de este trabajo, se define al emprendedor turístico mapuche (y al turismo mapuche) como aquel que tiene el conocimiento de la cosmovisión y lengua, promueve la armonía con el medio ambiente y genera una experiencia cultural genuina y auténtica (SERNATUR 2011).

Este tipo de convenios interinstitucionales a nivel nacional y regional entre SERNATUR y CONADI serán claves para el desarrollo del turismo indígena en diferentes partes del país, fomentando acciones como capacitación de guías turísticos, generación de material de difusión, realización de seminarios, aportes a infraestructura y procesos de formación y giras internacionales y nacionales para conocer experiencias de turismo. El viaje y tener la experiencia de ser turista, conocer otras culturas, es un elemento clave en la transferencia y formación del llamado emprendedor indígena, tal como destacan diversos entrevistados y entrevistadas respecto a la relevancia de conocer otras experiencias de turismo indígena que les ha permitido aplicar estos conocimientos en sus propios territorios.

Las políticas nacionales para el fomento del turismo indígena se fortalecerán con la nueva institucionalidad turística luego de la promulgación en el año 2010 de la Ley $\mathrm{N}^{\circ} 20.423$ del Sistema Institucional para el Desarrollo del Turismo, que crea la Subsecretaria de Turismo, dependiente del Ministerio de Economía, Fomento y Turismo. Un actor relevante en este proceso de instalación del turismo indígena es una organización privada llamada Travolution, creada el 2011, que en conjunto con organizaciones indígenas realizaron cuatro Encuentros Nacionales de Turismo Comunitario entre el 2011 al 2015. Estos encuentros agruparon a diferentes emprendedores indígenas del país, donde paulatinamente se incorporaron agentes públicos.

Este proceso se cristalizó en el año 2015 cuando se realizó en Puerto Varas, ciudad del sur de Chile, el Foro Internacional de Turismo Indígena en el marco de ATTA (Cumbre Mundial de Turismo Aventura), liderado por la World Indigenous Tourism Alliance WINTA y organizaciones chilenas ligadas al turismo, que permitió posicionar el turismo indígena dentro del aparato público.

A partir del año 2015, la Subsecretaría de Turismo comienza a trabajar el concepto de turismo indígena, como parte de su política de diversificación de productos y como una preocupación interministerial en la cual se construyen hasta hoy una agenda para el desarrollo del turismo indígena en Chile. Esto tomó fuerza a comienzos del segundo gobierno de la ex presidenta Michelle Bachelet, dándose una conjunción de situaciones que permitieron que intereses de ciertos funcionarios se complementaran con aquellos de organizaciones privadas. Ese mismo año, se constituyó la llamada Mesa Nacional de Turismo Indígena, compuesta por los principales entes del Estado que se relacionan con la industria turística y el mundo indígena, tales como Subsecretaría de Turismo, SERNATUR, CONADI, Consejo Nacional de la Cultura y las Artes (actual Ministerio de las Culturas, las Artes y el Patrimonio) e INDAP con su Programa Turismo Rural. Cada una de estas instituciones tendrá diversas formas de concebir el 
turismo indígena, que oscilan entre una alternativa de desarrollo económico, de fortalecimiento identitario y de encuentro intercultural (de la Maza 2016).

Esta instancia impulsó diversos estudios y acciones, ejecutados por agentes privados como ONGs y universidades, y que van a tender a consolidar el turismo indígena en Chile. Estos estudios buscaron diagnosticar la situación del turismo indígena y proponer estrategias de desarrollo y gobernanza. Es así, que desde la institucionalidad pública se retoma el concepto de turismo indígena ya mencionado, tomando como referencia el propuesto en un documento generado por el Programa Orígenes en el año 2003 (Orígenes 2003).

Estas acciones aportaron a constituir una red de emprendedores y líderes indígenas de todo el país que se organizaron en la Asociación Nacional de Turismo Indígena, reconocida con personalidad jurídica por la CONADI en el año 2017 que tiene un rol relevante hasta el presente. Al mismo tiempo, las experiencias regionales de turismo indígena también desarrollarán otras redes asociativas que vinculan a emprendedores turísticos indígenas.

\section{El rol de los mediadores institucionalizados}

El análisis de las políticas y programas públicos relativos al turismo indígena permite identificar el rol de mediadores en el diseño e implementación de dichas acciones. En este análisis, uno de los actores claves son los agentes públicos o privados que van a influir en el diseño e implementación de la política pública turística indígena, tanto por estar dentro de la institucionalidad y tener un rol relevante en la instalación y negociación interna, o por estar fuera de la institucionalidad, pero que por diversos motivos se convierten en contrapartes técnicas y legitimadas, y comprenden los llamados mediadores turísticos institucionalizados.

Los agentes que lideran esta acción como mediadores (pertenecientes a instituciones públicas o privadas) toman este rol clave en la política pública por razones tales como la trayectoria y experiencia en el rubro turístico, los vínculos políticos o personales de los que lideran, y/o el reconocimiento público que se van construyendo en el mismo proceso de construcción de política. Como consecuencia, las fronteras entre lo público y privado en el diseño e implementación de acciones estatales se diluyen producto de la influencia que asumen estos agentes, como se ilustra en este extracto de entrevista a un consultor privado:

\begin{abstract}
Nosotros hemos ido aprovechando las oportunidades que se nos presentan más que definir qué licitaciones se deberían hacer. Ahora, yo te diría, habiendo transcurrido tres o cuatro años yo creo que es innegable que de alguna manera está nuestra influencia en los proyectos que hoy en día se están lanzando pero no es porque nosotros hayamos hecho lobby (...). Lo que sí es justo decir, es que nosotros desde hace mucho rato tenemos clara la película y venimos, como empujando cuales son las líneas principales de acción que deberían hacerse en torno a política pública en turismo indígena en Chile (entrevista Consultor especializado en Turismo Indígena).
\end{abstract}

Como se ha mostrado, el funcionamiento de la política pública permite identificar diversos espacios borrosos del Estado para que estos intermediarios asuman roles protagónicos en el desarrollo del turismo indígena, como por ejemplo, la generación de alianzas y vocerías con algunas organizaciones indígenas y funcionarios estatales; pero, por otro lado, también suscitan detractores en algunos grupos. Esto se ha constatado en diversas experiencias observadas donde los intermediarios asumen un rol de liderazgo sobre la problemática indígena en diversos niveles y se convierten en contrapartes políticas tanto de las instituciones públicas hacia las organizaciones y emprendedores indígenas, como desde las organizaciones a las instituciones. Sin embargo, las organizaciones y líderes de turismo indígena han generado sus propias formas de incidir y de representación que hoy permite que algunos de ellas sean reconocidas como contrapartes de las instituciones públicas y que tengan condiciones para negociar e incorporar su impronta indígena y organizacional.

Esto también es posible de constatar cuando la política nacional de turismo indígena está generándose. Los funcionarios-mediadores que buscaban fortalecer el turismo indígena, sensibilizaron a otros agentes o burócratas respecto a este tipo de turismo al interior 
de la institucionalidad, proponiendo la generación de estudios. Estos fueron adjudicados por organizaciones privadas, cuyos resultados promovieron nuevos estudios más profundos y aplicados, los cuales son nuevamente licitados y adjudicados por estas u otras organizaciones privadas. Este proceso de instalación del turismo indígena permitió que los mediadores fueran poco a poco fortaleciendo su expertise y, por tanto, lograr tener una inicidencia cada vez mayor. Esto también va unido de la capacidad de los líderes y organizaciones indígenas, algunas con una relevante trayectoria política, que negociaron y presionaron, hasta el presente, la instalación de la política, fortalecidos a su vez por su participación en capacitaciones, giras y acceso a recursos concursables desde la institucionalidad pública. De esta forma, estos líderes y organizaciones indígenas son fundamentales para el sustento de la política para el turismo indígena, que en un contexto de conflicto indígena, como el llamado "conflicto mapuche" no podría desarrollarse.

Por último, otro ejemplo, es la forma en cómo se instaló desde el 2007 el concepto de turismo mapuche en la Región de la Araucanía. Los antecedentes y los relatos de algunos de las personas claves que han sido entrevistadas, muestran que la política regional de turismo indígena llamada turismo mapuche toma un camino más descentralizado. Los mediadores institucionalizados corresponden a funcionariosmediadores del sector público que asumieron un rol de liderazgo a fines del segundo periodo presidencial de Bachelet para diagnosticar y generar una propuesta específica de turismo indígena llamada turismo mapuche. Este concepto fue construido y apropiado por los emprendedores mapuche de la Araucanía. Esto ha permitido que en los últimos 10 años se incrementara considerablemente la oferta de turismo mapuche en la región, delineándose esta actividad como una opción económica relevante. Tanto es así, que el programa del segundo gobierno de Sebastián Piñera, llamado el Plan Impulso, tiene como uno de sus ejes estratégicos de activación económica el fortalecimiento del turismo. Sin embargo, en este periodo estos mediadores-institucionalizados del turismo mapuche han tenido un rol más secundario, asumiendo con más fuerza los mediadores-públicos y privados que estaban operando a nivel nacional. Es decir, en el contexto donde el turismo indígena toma mayor fuerza a nivel de política pública nacional, se hegemoniza frente a la regional.

\section{Lo Estructural: La Irrupción del Turismo en los Territorios Indígenas}

\section{Violencia estructural en el turismo}

La llegada del turismo a los territorios indígenas impone cambios no solo en el paisaje y las actividades económicas en dichos territorios indígenas, sino que también en las relaciones entre agentes sociales y económicos que producen desigualdad, exclusión social y degradación ambiental para las poblaciones locales. Esta irrupción tiene como trasfondo lo que Büscher y Fletcher (2017) han llamado violencia estructural en el turismo, que se asocia al concepto de poder estructural que se expresa en las relaciones que rigen la economía y la organización política y el proceso de formación de ideas (Wolf 2001). Estas formas de poder se traducen en violencias vinculadas a relaciones estructurantes de la sociedad que se expresan en diversos niveles y espacios, una de ellas las relaciones construidas bajo el turismo.

Respecto al turismo, la violencia estructural se entiende como aquel proceso de turistificación que se da en un contexto histórico de desigualdad política, social, cultural y económica, y que redunda en una profundización de las desigualdades existentes, de la segregación espacial de los grupos y de los impactos negativos sobre el medio ambiente. Se produce una dinámica de desposesión basada en relaciones asimétricas hacia la población local por parte de agentes externos que buscan rentabilizar el capital invertido en el sector turismo. Lo anterior tiene directa relación con los procesos de privatización de bienes comunes tales como la tierra, agua y paisajes (Fairhead et al. 2012).

La violencia estructural se manifiesta de diferentes formas, no solo en profundizar las relaciones de poder y dominación, sino también en la promoción de una oferta desconectada de las realidades de los destinos y una mercantilización de la cultura a veces sin participación o una participación marginal de sus protagonistas. La mayor parte del turismo cultural depende de la explotación de las diferencias étnicas/culturales y de las condiciones de vida de la población, muchas veces en condiciones de pobreza. Ello implica la creación de valor asociada al ofrecimiento de productos para el consumidor promovidos por los destinos.

Ello también genera que las expectativas de los turistas y agentes turísticos, tanto de sus habitantes 
como de agentes externos, se orienten al proceso de mercantilización del turismo, disminuyendo o perdiendo su vínculo con las realidades locales, proceso en el cual se pueden generar las llamadas burbujas de turismo, aislando a los turistas para no ser molestados con temas mundanos o políticos. Esto deja al turista fuera de un ambiente y contexto socio-histórico particular, aun cuando los productos del turismo son derivados del mismo contexto. De esta manera, el turismo puede negar la existencia de un mundo más complejo, y con ello simplificar la realidad, que en vez de abrir la mente del turista, puede terminar reforzando estereotipos y prejuicios.

\section{La burbuja del turismo indígena}

En el contexto chileno, donde impera el modelo neoliberal impuesto desde la dictadura militar, las desigualdades sociales y económicas son condicionantes profundas de la vida de los chilenos, que se agudiza en los sectores de la sociedad más excluidos, particularmente los pueblos indígenas, quienes han vivido bajo diversas formas de desigualdad a las que se suman otras condiciones relacionadas al ámbito político e histórico constitutivos de estas relaciones, que hoy se siguen expresando por la falta de reconocimiento político.

$\mathrm{Al}$ analizar las acciones públicas y la promoción turística que fomenta el turismo indígena se observa una distancia del conflicto político indígena. Sin duda, tiene relación con una oferta de turismo indígena que quiere ser atractiva para el visitante frente a una visión negativa o conflictiva de los espacios a visitar. Sin embargo, en los contextos indígenas de turistificación se manifiestan también de una u otra forma los conflictos estructurales e históricos entre los pueblos indígenas, el Estado, empresas y otros.

Esto se expresa con mayor fuerza en la región de la Araucanía, en la cual el conflicto mapuche toma un rol fundamental de demanda y reivindicación en contra de políticas estatales asociadas a la reducción de los espacios territoriales, la falta de agua y el impacto del modelo económico que afecta las diversas dimensiones de la vida cotidiana de las comunidades indígenas. Esta manifestación de conflictos estructurales no está ajena a otros territorios indígenas turistificados, como en San Pedro de Atacama, donde se identifican diversos problemas y conflictos asociados al control de su territorio ya sea con la minería o el propio turismo, lo que ha generado diversas acciones como el cierre de algunos lugares de atractivo turístico por los propios atacameños. O en Isla Rapa Nui con los problemas relativos a demandas territoriales y control del turismo de masa, que implicó que en el año 2015 el Parque Nacional Rapa Nui estuviera cerrado o con accesos limitados debido al control ejercido por el llamado Parlamento Rapa Nui y la demanda general de la población de la isla, que lleva a un acuerdo durante el segundo gobierno de Michelle Bachelet que establece una institucionalidad indígena para la gestión y administración en comodato del Parque con la Comunidad Ma'u Henua.

En general, en la revisión de guías turísticas, en folletos de promoción y las web institucionales de turismo, se identifica una oferta turística sobre una forma de vida de los pueblos indígenas asociada a su cultura ancestral y comunitaria, lo que se traduce en la generación de un relato y producto turístico. Esto se constata con frases como las siguientes tanto a nivel nacional como internacional: "The indomitable mapuche"- "El indomable mapuche", "Mágico Territorio Ancestral", "Acércate a las culturas ancestrales" y "Experimenta un día único dentro de la verdadera cultura y comunidad mapuche urbana", "Vive la experiencia de compartir los saberes de la tierra"4.

La construcción del indígena promovido tanto desde lo público como lo privado, en muchas ocasiones promueve una invisibilización de las condiciones materiales, sociales y culturales más problemáticas, por ejemplo, asociadas a la presencia de industrias extractivas en el territorio o conflictos territoriales o a la pobreza, que finalmente representan las condiciones de desigualdad política y económica. Tal como se presentan en el encuentro turístico, buscan más bien retomar las particularidades únicas y ancestrales de las formas de vida indígena que perduran y se resignifican en el contexto actual, como una forma de promover en el turista esta experiencia única y auténtica. Esto es lo que se ha llamado la burbuja del turismo (Carrier y MacLeod 2005; Pereiro 2012). Las burbujas de turismo en donde los clientes son aislados de lo que ocurre fuera del ámbito del consumo que realizan, en donde el turismo niega la existencia de un mundo complejo y desarrolla una lógica de simplificación de la realidad.

Un caso emblemático es la Reserva privada de Huilo-Huilo de la Región de Los Ríos, en el cual se expresan relaciones de dominación plasmadas por la instalación forzada de un "imaginario mágico" y un 
discurso ecológico, con formas de trabajo desiguales sobre un territorio mapuche con una larga historia de violencia y resistencia (Huiliñir-Curío et al. 2019).

Por ejemplo, en esta frase de promoción:

En un lugar muy lejano, rodeado de imponentes montañas, en medio de la Selva Patagónica, sólo si tú te lo permites, podrás conocer a los seres mágicos de la Reserva Biológica Huilo Huilo y percibir el origen milenario del Bosque y los misteriosos vientos que envuelven estos lugares. Al internarnos en el Bosque, entre helechos, líquenes, musgos y numerosos seres invisibles que te observan desde las alturas de las copas o desde un pequeño escondite en el suelo blando y mullido (...) (Fundación Huilo Huilo s/f).

Este ejemplo replica en forma extrema lo que sucede en otros territorios indígenas del país, tal como la zona lacustre, en el sector sureste de la Región de la Araucanía, donde se promueven y usan elementos propios del pueblo mapuche en ofertas que no tienen ninguna relación con personas y familias mapuche, o lo mismo que sucede en San Pedro de Atacama en hoteles exclusivos que incorporan una identidad "andina" mientras los atacameños o lickanantay solo tienen una participación más bien asociada a servicios y a los costos del exceso de visitantes, tal como relevan dos funcionarios públicos:

... hay hoteles en los que se nota que hay trabajo de arquitectos santiaguinos, que hay ideas de profesionales que tienen visiones de afuera. Tú vas a habitaciones que son preciosas en adobe, pero no son creaciones de acá, sino que de personas de afuera que venden el paquete.... (entrevista Funcionario público, nivel comunal, San Pedro de Atacama).

... Las comunidades no han sentido los beneficios del turismo masivo pero si los costos del turismo producto de la basura, el ruido, la contaminación, la saturación de los espacios y la transculturalización ... (entrevista Funcionario Público, nivel regional, Región de Antofagasta).
Esto mismo se ha visto en otros lugares del mundo, donde investigaciones ratifican que el turismo no necesariamente involucra beneficios directos para sus habitantes locales, a pesar del uso de elementos culturales como forma de promoción (p.ej., Cohen 2016; Hitchcock 2000; Lee et al. 2017; Ondisho 2010; Yang y Wall 2008).

\section{Intermediarios turísticos tradicionales: tour operadores, agencias y guías}

Otro tema relevante para analizar la forma en que se impone el turismo en territorios indígenas es el rol que ocupan los agentes turísticos como los tour operadores, agencias y guías. San Pedro de Atacama es emblemático respecto a otros territorios altamente turistificados, ya que presenta una diversidad de agencias y guías locales quienes ofrecen los tours en el territorio atacameño más emblemáticos y difundidos en guías turísticas y redes sociales. Por un precio accequible y un tour de un par de horas, medio día o día completo se puede visitar o realizar las actividades distintivas. Además, fuera de estos circuitos masivos, existen agencias exclusivas que están asociadas a hoteles, que se encuentran orientadas a turistas que están dispuestos a pagar una importante suma de dinero para tener las mejores garantías de un tipo de turismo ya no masivo y de alta calidad. Asimismo, existen tour operadores que ofrecen las experiencias de turismo indígena, turismo científico como astronomía y arqueología, e incluso minería, orientados a grupos especializados como son estudiantes secundarios o universitarios nacionales o extranjeros, profesionales o académicos.

Se observó en terreno la iniciativa de un emprendedor atacameño que se propuso generar una oferta diferente de turismo en San Pedro de Atacama, incorporando elementos culturales y guías locales. Sin embargo, a medida que va desarrollando su iniciativa, surgieron diversas dificultades para posicionar su oferta como, por ejemplo, que la experiencia turística que ofrece era menos conocida, ya que muchos de los visitantes que llegan buscan acceder a los hitos turísticos del territorio promocionados a nivel nacional e internacional. Como parte de su oferta, instaló una oficina o agencia turística que incorporó todos los servicios (guía, transporte, tour, etc.), que a la larga no pudo sostener económicamente y debió cerrar. A diferencia, otras agencias existentes en el 
mercado de San Pedro de Atacama logran sobrevivir, ya que tienen un sistema de minimización de gastos al compartir las formas de transporte, los guías, las personas que atienden en las oficinas turísticas, etc. Los tour están hechos para un turista poco exigente que busca completar su lista de chequeo de visita de los principales atractivos que todo buen visitante y turista debe hacer en San Pedro de Atacama. Esta condición hace inviable que un tour operador trabaje solo y no se incorpore a la dinámica del resto de las agencias.

La visión de algunos de los tour operadores se sintetiza en esta frase de un tour operador tradicional de San Pedro de Atacama: “(...) el turismo es un negocio, el rol de la empresa es ganar dinero, es un error del Estado la generación de productos indígenas que nunca nadie va a ir a ver" (Taller de Retroalimentación, San Pedro de Atacama).

En otro contexto, en territorio mapuche, también fue posible observar la prevalencia de los agentes turísticos externos sobre los locales, quienes tienden a imponer una forma de hacer turismo indígena. Una tour operadora extranjera que ofrece a sus turistas, principalmente extranjeros, experiencias de turismo mapuche, comentó en la entrevista sobre las dificultades de trabajar con guías mapuche. Señaló que considera que los guías locales no tienen suficiente formación para atender a un turista extranjero que busca una experiencia auténtica, y que además no hablan inglés, por lo cual debe contratar a guías que traduzcan e incorporen más contenido a la experiencia, pues señala que lo que ofrecen los emprendedores mapuche muchas veces no cumple con las expectativas que buscan los turistas, por lo cual debe ser muy cuidadosa en identificar experiencias que realmente sean atractivas.

Otro situación observada en esta misma línea, fue cuando una emprendedora mapuche poco a poco fue generando sus propias formas de comercialización buscando convertirse en tour operadora local. Esto también ha sido incentivado por acciones estatales en la Región de la Araucanía por medio de cursos específicos de comercialización, de formación de tour operador, de fortalecimiento de redes y de inglés. Ella ha liderado y organizado redes y rutas de emprendedores mapuche en determinados territorios, que ha ofrecido en diversas instancias nacionales e internacionales. En una ocasión, tal como relata, un tour operador no indígena se contactó con ella queriendo ofrecer algunas de sus iniciativas, pero no la ruta completa que ella presenta, lo cual generó su molestia. Una vez más, el tour operador externo quiere decidir lo que ofrece según sus parámetros de lo que considera que espera el turista que recibe, intentando imponer su propia mirada externa del turismo indígena.

Considerando algunos de los casos mencionados, se puede señalar que el turismo masivo, en donde participan una gran cantidad de visitantes en actividades estandarizadas, vende productos turísticos homogéneos buscando reducir el costo por tour ofrecido (ClaverCortes et al. 2007). Es una práctica común de las agencias y tour operadores la coordinación de oferentes de servicios locales y la generación de alianzas que permitan compartir activos complementarios tales como infraestructura, equipos y capital humano (Erkus-Oztürk 2008; Tremblay 1998). Todo lo anterior permite el cobro de precios más bajos a cambio de tours más estandarizados, lo que afecta negativamente a la competitividad de pequeños operadores que buscan turistas que anden tras experiencias diferenciadas más allá del turismo masivo (Thomlinson y Getz 1996). Esta estandarización del producto permite además la contratación de mano de obra barata y con pocas habilidades, con la sola excepción de los requerimientos de lenguaje.

Los productos de turismo indígena se enfrentan a la naturaleza limitada de la demanda, lo que está ligado también a desventajas en la localización y accesibilidad, estacionalidad de ingresos y necesidades de capacidad mínima de operación, que permitan alcanzar un umbral crítico financiero que sustente el negocio en el mediano y largo plazo (Simonsen 2006).

Las características de la organización de turismo masivo de San Pedro de Atacama muestran que se ha recreado una estética común en términos de infraestructura de acomodación y una oferta de tours estandarizada que permite la contratación de la abundante mano de obra ofrecida por turistas ocasionales de habla inglesa o portuguesa, que fijan residencia temporal y que tienen poca relación con la historia y cultura indígena de la localidad. El hecho que el turismo masivo de naturaleza ofrezca servicios de tours similares concentrados en una serie de sitios (p.ej., Valle de la Luna, Geysers del Tatio, Laguna Cejar, Salar de Uyuni), permite que los tours operadores tradicionales implementen joint-ventures que no solo les otorgan beneficios por los menores costos de transporte y trabajo (vehículos, combustible y guías), sino que también, les permite reducir los riesgos de disrupciones en su oferta de servicios producto de fallas en infraestructura, equipos o capital humano. En cambio, la limitada demanda de turismo 
de intereses especiales en torno a experiencias de turismo indígena influye de manera perniciosa sobre la sustentabilidad económica de tours-operadores para este nicho de mercado, ya que no es posible aprovechar las economías de escala asociadas a tours masivos y estandarizados.

Es así que las relaciones y mediaciones que se establecen entre los tour operadores en sus niveles, internacional, nacional y local, generan diversos escenarios donde se establece una relación jerárquica respecto a cómo funciona el sistema, qué se ofrece, su nivel de exclusividad, la apropiación del servicio y la contratación de ciertos tipos de guías turísticos. Esto privilegia y refuerza a solo algunos empresarios turísticos, mientras en otros se profundiza su vulnerabilidad y exclusión, marcando una brecha con los emprendedores indígenas o entre ellos mismos.

\section{La Reivindicación Política desde el Turismo Indígena}

\section{Revitalización política-cultural y valoración de lo propio}

Diversas investigaciones muestran que el turismo que incorpora la variable cultural y étnica como fuente de distinción puede generar procesos de revitalización cultural e identitaria (de Azeredo Grünewald 2002). Existe cierto consenso en que el turismo indígena puede jugar un rol clave en el desarrollo de las comunidades indígenas en relación a lo político y económico a través de las posibilidades que este abre para un control del territorio y su patrimonio (Calfucura 2018). Este control permite potencialmente generar nuevas dinámicas de gobernanza, empoderamiento local y político, así como desarrollo económico (Coria y Calfucura 2012). Por ejemplo, con el caso Kuna, cuya expresión de turismo indígena apunta a reforzar su autonomía, no solo política sino también económica (De León 2016; Pereiro 2012; Peredo et al. 2015), o en México con los pueblos Maya (Kroshus 2003), en Brasil en Pataxó (de Azeredo Grünewald 2002), Alaska y Nueva Zelanda (Bunten 2010) y también algunos ejemplos mapuche (Pilquimán 2017; Rommens 2017).

Entre los elementos que señalan estos casos se encuentran el rol del turismo como un ámbito de fortalecimiento cultural que se relaciona a aspectos tales como el fortalecimiento de liderazgos, la construcción de una autenticidad dinámica, la legitimidad de lo propio, la resistencia frente a problemáticas territoriales e históricas y procesos constantes de renovación y creatividad cultural, y también a una oportunidad económica y de negocio. En las experiencias observadas de turismo en territorios indígenas en Chile es posible constatar diversas expresiones contestatarias al desarrollo turístico. De una u otra forma, esta reivindicación va de la mano con la irrupción y violencia estructural del turismo en los territorios indígenas.

El turismo indígena también puede generar diversas formas de valorar lo propio, recordar la historia, reconstruir la historia de despojo, vivenciar con mayor fuerza la instalación de agentes externos en su territorio y la apropiación de sus recursos, pudiendo incorporar elementos culturales e históricos como parte de la distinción de su oferta. Aquí el patrimonio o elementos identitarios asumen un papel fundamental para proyectar una continuidad histórica como un colectivo. Por ejemplo, estos dos extractos de entrevistas donde se reconoce el valor de su patrimonio natural y el turismo como una herramienta de desarrollo, junto con la particularidad del turismo indígena:

Nos dimos cuenta que vivíamos en una zona privilegiada por su hermosura porque es una belleza sobrecogedora que reúne el río, el mar y los humedales y también la presencia de las personas. Y vimos como una herramienta que pudiera mantener nuestra forma de vida, pero a la vez también posibilitar que otras personas también lo conocieran y eso como una herramienta para que la comunidad en sí pudiera contar con mejores condiciones de acceso principalmente(...). Y desde ahí surge esta perspectiva de tomar el turismo como una herramienta para el desarrollo, pero con una identidad y con respeto al entorno y a la cultura propia del lugar (entrevista Emprendedora Mapuche, Región de la Araucanía).

Una experiencia con familias mapuche, una experiencia de vida, a no sentirse turista sino que sentirse acogida a la familia, poder aprender a cocinar, la cosmovisión, la historia, a conectarse con la naturaleza y las personas (entrevista 
Emprendedor Mapuche, Región del Bío Bío).

De esta manera, los patrimonios cultural y natural se vuelven instrumentos estratégicos para la reivindicación de la identidad étnica y legitimidad como pueblo (Bustos 2015). Esto cobra especial relevancia en un contexto de creciente disputa de derechos de uso sobre el territorio producto de la expansión de actividades productivas que entran en tensión con los pueblos indígenas (Calfucura 2018).

\section{Control territorial indígena: Áreas Silvestres Protegidas y turismo}

Casos concretos y emblemáticos respecto a procesos de control y reivindicación de áreas silvestres protegidas han sido San Pedro de Atacama y Rapa Nui, donde el resurgimiento de la identidad y los procesos de reconocimiento y patrimonialización han permitido el empoderamiento de comunidades indígenas en un contexto de resistencia al extractivismo. En el caso del pueblo atacameño-lickanantay, desde la vuelta a la democracia se observa un proceso de reconocimiento y patrimonialización, promovido parcialmente desde el Estado, que se ve mezclado con demandas sociales y étnicas que se contraponen a la expansión de proyectos mineros en el territorio del Salar de Atacama (Bolados 2014). De esta manera la comunidad de Coyo establece la primera demanda para administrar el sitio arqueológico de la Aldea de Tulor en el año 1995, buscando tomar medidas para evitar su deterioro y fomentar su conservación (Bustos 2011). Demandas similares ocurrieron en la comunidad de Quitor respecto de su pukara, en la comunidad de Peine con sus pinturas rupestres, y en la localidad de Toconao y la Laguna de Chaxa, entre otras.

El traspaso de la administración de la Reserva Los Flamencos hacia las comunidades atacameñas ha resultado en mayores restricciones para las empresas de turismo. Esto no ha estado exento de problemas, pues como mencionamos, el turismo masivo en San Pedro de Atacama se ha desenvuelto históricamente en un contexto de laissez-faire -sin ningún tipo de regulación-, lo que ha creado la percepción dentro de los tour operadores o guías turísticos que existe libre acceso a los diferentes sitios dentro del territorio atacameño.
En los últimos años, los atacameños han generado diversas restricciones al uso de ciertos espacios que afectan tanto su vida cotidiana como sus recursos naturales, los cuales sin restricción se ven afectados por la instalación de nuevas industrias como fue, por ejemplo, los globos aerostáticos instalados por el año 2016, y rechazados por las comunidades afectadas, o el uso de rutas sin regulación como fue en lugar de Tara. Los anteriores conflictos no solo se dan con la industria de turismo masivo de San Pedro de Atacama sino que también con el Estado, como lo fue la decisión de triplicar las tarifas de acceso a Laguna Cejar en el año 2014, hecho que puso de manifiesto las dificultades que enfrentan las comunidades atacameñas para implementar control territorial, fomentar el uso sustentable del territorio y ejercer poder local frente a la industria de turismo masivo.

... si vienen otros y pagan su entrada, bien, y si eso nos da números rojos, bien también, no es un tema que nos preocupe (...). Cuando cobramos como comunidades en distintas partes se nos trata de ladrones, que nos interesa sólo la plata .... y no es sólo la plata, porque el tour operador trae un turismo que no puede controlarlo (...) nos pasó hace poco que llego un contratista (de la minería) y trajo un saco de sal y no se le ocurrió nada mejor que subir al cerro y escribir su nombre.

... este mundo occidental cree que puede venir acá y hacer lo que se le plazca, y está el pueblo indígena que dice que estos sitios son sagrados (...), se quiere una forma que la (comunidad) defina, no los tour operadores, que el tour operador se contacte con la comunidad y lleve al turista, pero que sea la comunidad la que maneje todo desde la comunidad adentro (Taller de Retroalimentación, Líder atacameño, San Pedro de Atacama).

El otro caso paradigmático de control territorial corresponde al Parque Nacional Rapa Nui, que cubre el $42 \%$ de la Isla, administrado por CONAF desde 1973 hasta el año 2018. Durante el periodo 20022015 se observa la irrupción del turismo masivo en la isla, pasando de 14 mil a 65 mil turistas (Instituto 
Nacional de Estadísticas (INE 2002); Corporación Nacional Forestal (CONAF 2015), un incremento del $364 \%$, al mismo tiempo que la población prácticamente se duplicaba (INE 2002, 2017). Esta situación amenazaba la calidad de los suelos y la disponibilidad de agua dulce para la población local (Figueroa y Rotarau 2016). Todo ello trajo, como señalamos anteriormente, que en el año 2015 y frente a la inercia del Estado, miembros del Parlamento Rapa Nui decidan hacerse cargo del parque, expulsando a los oficiales de CONAF, ocupándolo por cinco meses, hasta que el desarrollo de un plebiscito sobre la administración conjunta permitiera avanzar hacia mecanismos de planificación y gestión. Este proceso de empoderamiento y resistencia tuvo su culminación en diciembre del año 2017, cuando el Estado de Chile entrega una concesión por 50 años a la Comunidad Ma'u Henua para administrar el Parque Nacional Rapa Nui.

Bajo la nueva administración Rapa Nui, el control territorial y administración ha significado un aumento sustancial del personal para controlar el acceso ilegal y hacer efectiva la capacidad de carga máxima del parque, pasando desde 20 guías y guardaparques bajo la administración de CONAF hasta 200 agentes bajo la nueva administración, además del establecimiento de un límite a la venta de tickets de visita. El empoderamiento alcanzado por la población Rapa Nui no ha estado exento de problemas en su relación con el Estado, y esta tensa relación ha dificultado el acceso a recursos estatales, particularmente aquellos asociados al Fondo Nacional de Desarrollo Regional (FNDR). También se han generado conflictos internos vinculados a disputas políticas y de gestión de los recursos financieros asociados al parque nacional. No obstante esto último, las demandas de control administrativo sobre el parque por parte de los Rapa Nui son una clara expresión de sus reclamos territoriales y políticos de autonomía. También abrió el camino para la transferencia del control administrativo sobre el territorio, sentando un precedente para la gestión indígena de las actividades turísticas en otras áreas protegidas vinculadas a los territorios indígenas.

Finalmente, en la zona de la Araucanía, las comunidades mapuche están en pleno proceso de demanda por la protección del Parque Nacional Villarrica, que comprende varias comunas de la Región de la Araucanía y Los Ríos. Esta demanda se origina por la defensa del Volcán Villarrica o
Rukapillan, que comprende parte importante del Parque y que se ha visto afectado por diversos proyectos, tales como el interés de crear un nuevo centro de sky, caminos que atraviesan el parque, desarrollo de inmobiliarias y concesiones de diverso tipo. El principio de lucha de las comunidades organizadas y autoconvocadas tiene relación al reconocimiento y reclamo del rol espiritual, cultural y natural del Volcán para el pueblo mapuche, lugar de significación cultural donde nacen las aguas y están los lawenes (corresponde al nombre genérico mapuche de plantas medicinales). Este accionar ha generado una mayor profundización de los relatos y conocimientos mapuche vinculados al volcán y posiblemente a una demanda futura de áreas que comprenden al Parque Nacional Villarrica. Se constata que el desarrollo turístico de la zona lacustre es una amenaza para las formas culturales mapuche, pero también para el turismo mapuche que se desarrolla en el territorio afectado. Por lo cual, el turismo pasa a conformar una argumentación importante para la reivindicación y autonomía territorial en diversos lugares y asociada fuertemente a las áreas silvestres protegidas (Coria y Calfucura 2012).

\section{El relato turístico indígena}

Una forma más de resistencia política se visualiza en la importancia que adquiere el relato en el turismo indígena. Como se ha señalado, el relato es un elemento central de distinción del turismo indígena, que ha sido fomentado fuertemente por acciones estatales.

El relato turístico debe construirse para satisfacer la experiencia y expectativa del turista que busca empaparse de la cultura local. Pero también genera una discusión interna en las comunidades sobre lo que se quiere y puede ofrecer, como se ilustra en este extracto de entrevista a un emprendedor mapuche:

... empieza la discusión de cómo nosotros queremos que el turista nos vea, pero, al mismo tiempo, qué queremos ofrecer al turista, qué es lo que está permitido y que es lo que no está permitido, ahí, entramos, nuevamente, en el conocimiento mapuche, hasta dónde estamos permitidos de mostrar" (entrevista Emprendedor Mapuche, Región de los Ríos). 
Por otra parte, diversos cursos de formación buscan alentar este proceso de construcción de un relato turístico ya sea en forma individual o colectiva por territorios. A partir de la observación de casos de formación en la Región de la Araucanía, ha sido relevante la constatación de que la construcción del relato se da en muchos casos con facilitadores/profesores mapuche o por medio de la investigación que realizan los mismos emprendedores. En los casos en que los formadores son mapuche, suelen tener una trayectoria relevante en ámbitos de revitalización cultural y reivindicación política del territorio. En los espacios de formación los temas abordados son diversos, como lengua, historia, cosmovisión, significado de vivienda mapuche, gastronomía y género. En cada uno de estos módulos se realizan conversatorios donde una persona lidera al grupo generando una activación de la memoria a los participantes y una reflexión sobre los procesos que cada uno ha vivido a lo largo de su vida. Esta metodología sin duda permite un proceso de revitalización y profundización de la toma de conciencia respecto a los procesos de pérdida territorial y cultural, cuestión que se ha expresado en los temas que se reflexionan y discuten al interior de cada taller.

Otra forma de capacitación observada, que genera efectos similares, es cuando se promueve la construcción del relato turístico a partir de una metodología de puesta en valor del patrimonio, donde los participantes de la actividad deben investigar sobre la historia de sus territorios y los contenidos culturales mapuche de su emprendimiento. Al igual que los talleres liderados por formadores mapuche, en esta metodología el protagonista en la construcción del relato es el mismo emprendedor, que por medio de entrevistas con personas mayores y familiares no solo da valor a su propio territorio e historia, sino que también profundiza el conocimiento sobre las formas de despojo y pérdida cultural que han experimentado.

Por ejemplo, en un taller una persona se sentía acongojada porque no hablaba la lengua mapuche y eso podía influir en su oferta de turismo mapuche. Sin embargo, un relator le señaló que lo relevante es compartir por qué hoy no se habla la lengua y cuáles son las razones. Ese tipo de testimonio podía ser muy relevante para un turista interesado en conocer a los mapuche y su forma de vida actual, no la ofrecida en la llamada "burbuja" del turismo.

A pesar de que la intencionalidad de la construcción del relato turístico mapuche está asociada a fortalecer la distinción del emprendimiento turístico indígena, se convierte en una fuente de activación y concientización más profunda de procesos de despojo y pérdida cultural y, a su vez, potencia procesos de revalorización cultural e histórica. Esto puede estar asociado a procesos crecientes de demandas y reivindicación territorial que van más allá del turismo y que se presentan frecuentemente en el territorio mapuche.

\section{Conclusiones}

El artículo abordó el turismo en territorios indígenas desde una perspectiva política que buscó desentrañar diversas formas en como este se manifiesta en las relaciones de poder entre el Estado, intermediarios, agentes privados y pueblos indígenas en Chile. Este es un tema de vital importancia para el país dado el dinamismo y crecimiento del sector turismo durante los últimos 20 años y su expansión sobre una parte importante de los territorios indígenas, como San Pedro de Atacama, Rapa Nui o la Región de la Araucanía. Vemos que la turistificación trae consigo la transformación de estos territorios y, junto con ello, cambios sobre las construcciones sociales que sustentan las relaciones entre comunidades indígenas y agentes externos, sean estos organismos gubernamentales o un cambiante sector empresarial. Los impactos sobre derechos de propiedad, accesos, ecologías y cultura generan tensiones sobre el control de recursos y paisajes.

Se analizó la construcción de la política pública orientada al turismo indígena contrastando diversas genealogías tanto a nivel regional como nacional. Si bien se ha observado un proceso de creciente importancia del turismo indígena para el Estado, que ha implicado el desarrollo e implementación de diferentes iniciativas de apoyo a los "emprendedores" indígenas, también fue posible identificar el surgimiento de actores claves, los denominados mediadores institucionalizados. Estos agentes, a través de su espacio de poder, han incidido como expertos en esta construcción de políticas que se distancia de otras genealogías como es la política indígena en Chile, y responden en etapas iniciales al vacío existente -de conocimientos y capacidades en el Estado- para llevar a cabo políticas de turismo indígena. Un proceso de reciente empoderamiento de emprendedores y comunidades indígenas ha permitido que durante los últimos años sean los actores indígenas quienes comienzan a jugar un rol más preponderante en la implementación de políticas de turismo en territorios indígenas, especialmente en el caso de las áreas 
protegidas traspasadas desde el Estado. Con ello han sido posible una mayor participación de los pueblos indígenas en el diseño, implementación y resultados de las políticas de turismo indígena.

Desde esta perspectiva son relevantes los conceptos de violencia estructural y reivindicación política relacionados a la turistificación de los territorios indígenas y del desarrollo del turismo indígena. Esta violencia estructural se da cuando la irrupción del turismo -muchas veces masivo- en los territorios indígenas ocurre en un contexto histórico de desigualdad política, social, cultural y económica, y donde el turismo profundiza estas desigualdades existentes, se traduce en la segregación espacial de los grupos, y generas impactos negativos sobre el medio ambiente. Las burbujas de turismo han tendido a aislar a los turistas de las realidades y conflictos existentes en los territorios, invisibilizando las demandas de las población indígena local. Por otra parte, el emprendedor turístico se contrapone al usuario, ya que este es el que visualiza una alternativa para salir de la pobreza y ser autosuficiente económicamente. Ambos aspectos se relacionan y no son excluyentes. La violencia estructural, generalmente promovida por actores externos al territorio, tanto empresarios, funcionarios públicos, expertos como académicos, genera procesos internos en los territorios que pueden llevar a potenciar demandas históricas de control territorial y activación de una memoria de despojo y pérdida cultural a partir de la construcción del relato y de la distinción turística. Esto a su vez, se asocia a la reivindicación política del territorio, donde el turismo indígena, promovido por las instituciones públicas, se convierte en una herramienta de lucha.

Finalmente, el turismo indígena, promovido por las instituciones públicas, se contrapone con otras políticas públicas neoliberales que fomentan el uso indiscriminado del territorio a partir del llamado extractivismo. Es así como la mayor parte de los emprendedores indígenas entrevistados elaboran una concepción del turismo indígena que se construye en relación con la comunidad y que busca fomentar el cuidado y resguardo de la naturaleza y de la cultura indígena. Esto tiene una clara contraposición con las consecuencias de la implantación de industrias como la minería y la actividad silvo-agrícola que han tenido impactos relevantes sobre recursos como el agua, la biodiversidad y el paisaje, y sobre las condiciones de vida las comunidades indígenas. Del mismo modo, el turismo indígena viene a plantearse como un enfoque de empoderamiento y desarrollo local que se diferencia de un turismo masivo desregulado que ha tendido a afectar negativamente la sustentabilidad de los territorios indígenas.

Concluimos con que el turismo indígena en Chile se encuentra en una fase de expansión de capacidades que ha permitido un creciente empoderamiento de los pueblos indígenas en diversos ámbitos, ya sea en el diseño de las políticas públicas como en la implementación de iniciativas de control del territorio y mejoras de las condiciones de vida. Lo anterior no implica que no persistan desafíos, ya que aún hay necesidades relacionadas al diseño de gobernanza para la gestión del turismo y al involucramiento de la población local que necesitan ser abordadas. Estas problemáticas sin duda significarán nuevos procesos políticos entre actores indígenas, el Estado y actores privados de particular relevancia para el desarrollo de los pueblos indígenas en Chile.

Agradecimientos: Este artículo se enmarca bajo el proyecto Fondecyt Regular N¹170236: "Turismo y Pueblos Indígenas: un estudio de los discursos, prácticas y políticas públicas en tres territorios de Chile" y al Centro de Estudios Interculturales e Indígenas-CIIR CONICYT-FONDAP $\mathrm{N}^{\circ} 15110008$. También agradecemos a los evaluadores anónimos que sin duda enriquecieron el artículo con sus sustantivos comentarios.

\section{Referencias Citadas}

Appadurai, A. (ed.) 1991. La Vida Social de las Cosas. Perspectiva Cultural de las Mercancías. Grijalbo/Conaculta, México DF.

Barabas, A. 2010. El pensamiento sobre el territorio en las culturas indígenas de México. Avá Revista de Antropología 17:1-15.

Barragán, R. y F. Wanderley 2009. Etnografías del Estado en América Latina. Íconos. Revista de Ciencias Sociales 34:21-25.

Bolados, P. 2014. Los conflictos etnoambientales de "Pampa Colorada" y "El Tatio" en el Salar de Atacama-Norte de Chile. Procesos étnicos en un contexto minero y turístico trasnacional. Estudios Atacameños 48:228-248.
Bunten, A. 2010. More like Ourselves: Indigenous Capitalism through Tourism. The American Indian Quarterly 34 (3):285-311.

Büscher, B. y R. Fletcher 2017. Destructive creation: capital accumulation and the structural violence of tourism. Journal of Sustainable Tourism 25 (2):651-667.

Bustos, C. 2011. Grupos originarios, patrimonio cultural y turismo indígena en el desierto de atacama (Chile). En Turismo y Patrimonio, Entramados Narrativos, editado por L. Prats y A. Santana, ACA y PASOS, RTPC, El Sauzal, Tenerife. 
Bustos, C. 2015. La producción de "etnomercancías" en el contexto turístico atacameño. Revista Lider 27:138-171.

Calfucura, E. 2018. Governance, land and distribution: A discussion on the political economy of community-based conservation. Ecological Economics 145:18-26.

Carrier, J. y D. MacLeod 2005. Bursting the bubble: The sociocultural context of ecotourism. Journal of the Royal Anthropological Institute 11:315-334.

Claver-Cortes, E., J. Molina-Azorín y J. Pereira-Moliner 2007. Competitiveness in mass tourism. Annals of Tourism Research 34 (3):727-745.

Cohen, E. 2016. Ethnic tourism in mainland Southeast Asia: the state of the art. Tourism Recreation Research 41 (3):232-245.

Comaroff, J.L. y J. Comaroff 2011. Etnicidad S.A. Katz Editores, Madrid.

CONAF 2015. Estadísticas de Visitas al Sistema Nacional de Areas Silvestres Protegidas. Corporación Nacional Forestal, Santiago.

Coria, J. y E. Calfucura 2012. Ecotourism and the development of indigenous communities: The good, the bad, and the ugly. Ecological Economics 73 (C):47-55.

De Azeredo Grünewald, R. 2002. Tourism and cultural revival. Annals of Tourism Research 29 (4):1004-1021.

De la Maza, F. 2016. State conceptions of indigenous tourism in Chile. Annals of tourism Research 56:80-95.

De la Maza, F. 2017. State interactions in indigenous and intercultural contexts. Shared life trajectories between the public employee and the user. Anthopos A112 (2):455-466.

De la Maza, F. 2018. Tourism in indigenous territories: impact of public policies and the tourism value of indigenous culture. Journal Latin American and Caribbean Ethnic Studies 13 (1):94-111.

De la Maza, F. y C. Bolomey 2019. Persistence and Changes in State dependence in a mapuche indigenous territory, Chile. Critique of Anthropology 40 (1):146-168.

De León, C. 2016. Resignificación política del manejo de los recursos naturales en una comunidad indígena de Panamá: Los gunas y el turismo. Ecología Política 54:45-50.

El Mercurio. 2017. Lonely Planet destaca a Chile como mejor destino para viajar. 25 de Octubre. http://www.economiaynegocios. cl/noticias/noticias.asp? id $=410699$ (Fecha de consulta: 8 septiembre 2020).

Erkus-Oztürk, H. 2008. The Role of Local and Global Networking for Tourism Firms and Clusters: The Case of Antalya. Thesis $\mathrm{PhD}$ in City and Regional Planning, School of Natural and Applied Sciences, Middle East Technical University, Ankara.

Fairhead, J., M. Leach y I. Scoones 2012. Green Grabbing: a new appropriation of nature? The Journal of Peasant Studies 39:237-261.

Fan, K.H.F., T.C.Chang y S.L. Ng 2020. The Batek's dilemma on indigenous tourism. Annals of Tourism Research 83102948 https://doi.org/10.1016/j.annals.2020.102948.

Fedetur 2019. Chile gana por segunda vez consecutiva World Travel Awards, como mejor destino de turismo aventura. Federación de Empresas de Turismo de Chile. https://fedetur.cl/turismo_chile/ chile-gana-por-segunda-vez-consecutiva-world-travel-awardscomo-mejor-destino-de-turismo-aventura/ (Fecha de consulta: 8 septiembre 2020).

Fernández, C., J. Cea, P. Santander y R. Melo 2015. Turismo de intereses especiales: investigación de mercado sobre las motivaciones desde la perspectiva del cliente. Revista Internacional de Administración y Finanzas 8 (1):51-68.

Figueroa, E. y E. Rotarou 2016. Sustainable Development or Eco-Collapse: Lessons for Tourism and Development from Easter Island. Sustainability 8:1093.

Fundación Huilo Huilo s/f. https://fundacionhuilohuilo.org/ difusion/seres-magicos/ (Fecha de consulta: 30 agosto 2020).

INE 2002. Censo de Población y Vivienda 2002. Instituto Nacional de Estadísticas, Santiago.

INE 2017. Censo de Población y Vivienda 2017. Instituto Nacional de Estadísticas, Santiago.

Hitchcock, M. 2000. Ethnicity and tourism entrepreneurship in Java and Bali. Current Issues in Tourism 3 (3):204-225.

Huiliñir-Curío, V., Zunino, H. y L. De Matheus 2019. Exclusión y desigualdad en localidades próximas a la Reserva Ecológica Privada Huilo-Huilo en el sur de Chile. ACME: An International Journal for Critical Geographies 18 (2):335-363.

Kroshus, L. 2003. Commoditizing culture: Tourism and Maya Identity. Annals of Tourism Research 30 (2):353-368.

Lee, W., J. Haddock-Fraser y M. Hampton 2017. Destination competitiveness: evidence from Bali. Current Issues in Tourism 20 (12):1265-1289.

MacLeod, D.V.L. y J.G. Carrier (eds.) 2009. Tourism, Power and Culture. Anthropological Insights. Channel View Publications, Bristol.

Nielsen, N. y E. Wilson 2012. From invisible to indigenous-driven: A critical typology of research in indigenous tourism. Journal of Hospitality and Tourism Management 19:67-75.

Nogués-Pedregal, A. 2019. Anthropological contributions to tourism studies. Annals of Tourism Research 75:227-237.

Ondisho, T. 2010. Tourism, Power and Politics: The Challenges of Maasai Involvement in Tourism Development. Thesis PhD. in Social Anthropology at Massey University of New Zealand, Palmerston North.

Orígenes, P. 2003. Turismo: Una Apuesta al Desarrollo de las Comunidades Indígenas de Chile. Programa Orígenes MIDEPLAN-BID, Santiago.

Peredo, B., A. Ordóñez y V. Belohrad 2015. Past and present perspectives on indigenous tourism in the Pastaza Province of Ecuador: The case of Kapawi. The International Indigenous Policy Journal 6 (4):Art. 7.

Pereiro, X. (coord.) 2012. Los Turistores Kunas. Antropología del Turismo Étnico en Panamá. Universitat de les Illes Balears, Palma.

Pereiro, X. 2013. Los efectos del turismo en las culturas indígenas de América Latina. Revista Española de Antropología Americana 43 (1):155-174.

Picard, M. 2003. Touristification and balinization in a time of reformasi. Indonesia and the Malay World 31 (89):108-118. 
Pilquimán, M. 2017. Turismo comunitario en territorios conflictivos. El caso de las comunidades indígenas mapuche en la Región de los Ríos en Chile. Geopolítica(s) 8 (1):11-29.

Rommens, D. 2017. Living the territoriality: Mapuche tourism and development. Cultura, Hombre, Sociedad (CUHSO) 27 (1):51-88.

Schavelzon, S. 2008. Antropología del Estado en Bolivia: verdades sagradas, farsas políticas y definiciones de Identidad. Cuadernos de Antropología Social 28:67-84.

Simonsen, R. 2006. Joint ventures and indigenous tourism enterprises. Tourism Culture \& Communication 6:107-119.
SERNATUR 2011. Fundamentos el Turismo Mapuche y Orientaciones para su Desarrollo, Región de la Araucanía. SERNATUR/CONADI/PTI/Seremi de Salud, Región de la Araucanía.

Subsecretaria de Turismo 2019. Anuario de Turismo 2018. Santiago.

Theodossopoulos, D. 2013. Emberá indigenous tourism and the trap of authenticity: Beyond inauthenticity and invention. Anthropological Quartely 86 (2):397-426.

\section{Notas}

1 Gulumapu corresponde a la denominación que se le da al territorio mapuche ubicado al lado oeste de la Cordillera de los Andes, que junto al Puelmapu (lado este) comprende el Wallmapu. En Gulumapu se denomina Lafkenmapu a la zona costera y Pewenmapu a la zona cordillerana.

2 Proyecto Fondecyt Regular 1170236: "Pueblos Indígenas y Turismo: Estudio de las prácticas, discursos y políticas públicas en tres territorios indígenas en Chile" (2017-2021)

3 Frases tomadas de diversas entrevistas asociadas al concepto de emprendedor indígena.

4 Frases obtenidas de diversos folletos y guía turísticas. La frase en inglés corresponde a Lonely Planet Chile \& Easter Island 2015. 
